Reseña

\section{María Fernández Moya. Multinacionales del castellano. El sector editorial español y su proceso de internacionali- zación (1900-2018). Madrid, Editorial CSIC, 2020, 291 pp. ISBN: 978-8400106591.}

Cada año, la Federación del Gremio de Editores de España publica un informe estadístico sobre el sector editorial del país. En el más reciente, se puso de relieve que la exportación de libros producidos en España alcanzó durante 2019 más de 529 millones de euros ${ }^{1}$. Estos informes, pero también los publicados por la Asociación de las Cámaras del Libro de España, muestran datos y apuntes muy interesantes sobre el comercio exterior del libro y, en conjunto, recalcan la importancia de la industria editorial en la economía en general y en el PIB en particular. Cómo se ha llegado a esa situación es el hilo vertebrador del libro que nos ocupa. Multinacionales del castellano. El sector editorial español y su proceso de internacionalización (1900-2018) aborda, de una manera clara y ordenada, la vertiente empresarial de una industria tan relevante, no solo por sus implicaciones económicas, sino también por su dimensión cultural.

María Fernández Moya, profesora en el Colegio Universitario de Estudios Financieros (CUNEF), dedicó su tesis doctoral al proceso de internacionalización del sector editorial. Defendida en 2017, fue galardonada con el Premio Extraordinario de Doctorado en la Universidad Complutense de Madrid. Ahora podemos disponer de un libro derivado de su investigación doctoral gracias a la Editorial CSIC. Este ensayo es interesante porque su interdisciplinariedad lo convierte en un volumen de interés para diversos campos del conocimiento. Desde la historia literaria hasta la historia empresarial, pasando por agentes implicados en la producción del libro, Multinacionales del castellano encontrará interlocutores en muy diversos ámbitos.

Este libro se compone de una introducción, de cuatro capítulos ordenados cronológicamente que abordan sucesivas etapas de la historia editorial española, de un quinto capítulo que presenta breves historias de cuatro editoriales (Espasa-Calpe, Salvat, Seix Barral y Planeta) y de un último capítulo reservado para compendiar los principales puntos desarrollados. Se aprecia en todo el volumen una unidad interna que conviene al tema que se trata.

La introducción resulta muy esclarecedora, y en ella la autora explica cuál es la pregunta central respecto al sector editorial: «¿Cómo se ha forjado un tejido competitivo a nivel internacional precisamente en una industria cultural?» (p. 14). Para responderla, se sirve de un marco teórico actualizado y,

\footnotetext{
${ }^{1}$ Disponible en: https://www.federacioneditores.org/img/documentos/ Informe_sector_editorial_esp2019.pdf
}

como apuntábamos al principio de la reseña, marcadamente interdisciplinar.

El primer capítulo, «La internacionalización del libro español antes de la Guerra Civil (1900-1936)», se centra en el primer tercio del siglo veinte. En él se aborda el papel estratégico de América Latina, así como las primeras iniciativas político-institucionales para impulsar el comercio exterior. El segundo capítulo, «La larga posguerra y la estrategia transatlántica de las editoriales españolas en el primer franquismo (1936-1959)», señala la relevancia de México y Argentina, y no olvida las acciones que emprendieron editores e intelectuales exiliados. Este capítulo dialoga provechosamente con investigaciones precedentes de Fernando Larraz, como Una historia transatlántica del libro. Relaciones editoriales entre España y América Latina (1936-1950) (2010) y Editores y editoriales en el exilio republicano de 1939 (2018).

El tercer capítulo, «El boom exportador. La edad dorada del libro español (1959-1975)», es ligeramente más amplio porque, entre otras razones, constituye el núcleo central del estudio de Fernández Moya. Aunque no se trate del tema principal, resultan muy interesantes los apuntes sobre aspectos contextuales. Por ejemplo, se detiene la autora en el problema del enfoque de la Editora Nacional en relación con la armazón ideológica del régimen (p. 113). Resulta muy pertinente que este capítulo se ocupe de la distinción entre el llamado libro "de masas" y el libro «de bolsillo» (p. 123), analizándolo desde el punto de vista empresarial. Esos apuntes se complementan con otras informaciones que contribuyen a dibujar un contexto histórico amplio de la historia de España. Así, en 1963 la industria editorial vivió un hito cuando fue declarada «de interés preferente» (p. 146). Vemos pues cómo la internacionalización del libro no se aborda de una manera aislada, sino que, considerando la importancia del sector editorial, permite obtener, además, una idea general de cómo iba evolucionando el país.

Es un aspecto muy positivo de este libro el hecho de que no solo se centre en las editoriales, sino que se detenga también en el papel de las distribuidoras (p. 70), de las agencias literarias y de las ferias del libro (pp. 129-130), pero también de nuevas figuras empresariales surgidas en las últimas décadas (p. 133). Se entra, así, en el cuarto capítulo, «Un sector editorial global, ¿y digital? (1975-2018)", con unas coordenadas que ayudan a comprender los desafíos a los que se enfrenta esta industria en la época actual. Este capítulo aporta informaciones y datos muy relevantes que ya no solo interesan a los especialistas, sino a cualquier lector o consumidor de libros. Me refiero, exactamente, al panorama crítico que se presenta en relación con Amazon y sus prácticas empresariales.

El quinto capítulo, "Trayectorias editoriales», presenta cuatro semblanzas de cuatro editoriales representativas e históricas. El título de cada una de ellas presenta el rasgo más definitorio. Termina el volumen con un apartado final en el que se 
recapitulan los principales temas desarrollados -cabe mencionar el apoyo visual y explicativo que suponen las numerosas tablas en las que se ordenan los datos, muchas de ellas de elaboración propia-. Fernández Moya reflexiona sobre las particularidades de las editoriales españolas a lo largo de los siglos veinte y veintiuno y las variables que han resultado determinantes en su expansión: el "conocimiento acumulado" y el "capital social» (p. 263). La autora también destaca la importancia de la estructura familiar, del área lingüística y de las virtudes de cada uno de los editores (muy interesantes las pinceladas que se aportan para definir a Salvat, Gili, Maucci y otros).
Apunta Fernández Moya que «los editores fueron pioneros en la internacionalización de la empresa española» (p. 257). Este volumen, en efecto, muestra con datos cómo ha tenido lugar un proceso de internacionalización en el sector editorial y cómo se han ido generando empresas multinacionales que suponen una parte importante del desarrollo económico de España.

Sofía González Gómez Grupo GICELAH (CSIC) 